\title{
Consideraciones sobre la actitud político-social de Rubén Darío*
}

\begin{abstract}
A
L proponernos estudiar la actitud político-social de Rubén Darío,

nos hallamos ante dos factores contradictorios entre si. Por una parte tenemos la opinión de ciertos autores contemporáneos de $\mathrm{Da}$ río; y, por la otra, la evidencia que en sentido contrario resalta de la propia obra del poeta. Si nos dejamos llevar por la pluma de un Leopoldo Lugones, un Rufino Blanco-Fombona, o un Enrique Gómez Carrillo, ${ }^{1}$ nuestro poeta resulta ya un conservador a machamartillo, monárquico y anti-republicano; ya un servil oportunista sin otra lealtad que al despotismo y al poder, o por lo menos un espíritu egoísta que, desde su torre de marfil, se mantuvo impasible ante los dolores de la humanidad.

Dario, innegablemente, fué ante todo un alma contemplativa, un creador de un mundo propio consagrado al culto de la belleza. Esta es la fase de su obra y de su personalidad que más se ha dado a conocer; $y, a$ pesar de la celebridad que han alcanzado algunas de sus composiciones de índole racial o continental, predomina persistentemente la tendencia de identificar el nombre del poeta con un mundo de fantasía y la ideal torre de marfil. En sus obras menos conocidas, sin embargo, hallamos a un Darío intensamente alerta a los sucesos del mundo contemporáneo, un espíritu amante del progreso en todas sus manifestaciones, $y$ un observador penetrante y sensitivo de los problemas de la humanidad. Hay aún más. En obras tales como las tituladas Poemas de juventud, Crónica política,

* Trabajo leído ante la Sección de Literatura Latinoamericana de la South Central Modern Language Association, reunida en Stillwater, Oklahoma, noviembre de 1953 .
\end{abstract}


y varias otras en que palpita la tradición política identificada con la niñez y la juventud del poeta, hallamos a un Darío que fué nada menos que campeón de causas en el terreno político-social.

A la edad de catorce años, el "poeta-niño", como se le llamaba en Nicaragua, ganó celebridad en todo el territorio centroamericano como paladín de las ideas más avanzadas de su tiempo. En poemas candentes de radicalismo, y en artículos inspirados en los ensayos del anticlerical Juan Montalvo, el poeta-niño se hizo cantor del Partido Liberal, cuyo programa revolucionario abarcaba la unión de las cinco repúblicas centroamericanas, la libertad política, la libertad del pensamiento, el progreso de la ciencia, la instrucción liberal y laica, los derechos políticos y económicos de las masas y luchaba contra la tiranía, la monarquía, el analfabetismo, el dogmatismo y el clericalismo. ${ }^{2}$ Fundiendo en un mismo escudo los colores del liberalismo francés y centroamericano, el juvenil poeta cantó en los siguientes términos en su oda "A Victor Hugo":

El Progreso sin fin, ese es tu lema y la insignia que lleva tu bandera.

El Progreso sin fin, ¿qué significa tal palabra? Pues bien: es Jesucristo predicando igualdad y unión al pueblo, y muriendo en su cruz: es Galileo ceñido de su fúlgida diadema que exclama: E PUR SI MUOVE, aun a despecho del Fanatismo cruel ... 3

La lealtad que a través de su vida mantuvo Darío a los ideales del Partido Liberal consta tanto en la obra como en la vida del poeta. A su vuelta de Chile en 1889 , el joven cuanto ya prestigioso autor de $A z u l$ se dedica de lleno a la causa de la Unión Centroamericana, que, como queda dicho, fué parte integrante del programa del Partido Liberal. Su estilo no ostenta ya el apasionamiento radical de sus poemas y escritos de adolescencia. Ahora sus escritos políticos revelan la convicción serena del ideal que persigue, el amor a su misión, y el espíritu sobrio de quien a plena conciencia asume una responsabilidad sagrada. Más tarde se recopilaron estos artículos en el tomo denominado Crónica politica, que desafortunadamente es uno de los menos conocidos entre los cuarenta y tantos volúmenes que salieron de la pluma del poeta. Entre dichos escritos. se encuen- 
tra ese valeroso y enérgico grito de protesta titulado "La historia negra de Carlos Ezeta", 1890, en que nuestro poeta toma la defensa del derrotado caudillo liberal Francisco Menéndez, y, despreciando las oportunidades que le brinda el victorioso general Ezeta, en términos nada inciertos echa en cara a éste los vergonzosos detalles de la traición que acababa de ponerlo en el poder. ${ }^{4} \mathrm{Y}$ por cierto que no fué ésta la única vez que Darío se pusiera de parte del vencido en lealtad a la causa liberal. En la obra titulada El viaje a Nicaragua, 1912, ya en el otoño de su vida, el poeta igualmente sale en defensa de otro caudillo liberal que a la sazón acababa de caer, José Santos Zelaya. ${ }^{5} \mathrm{Al}$ enumerar los beneficios aportados a Nicaragua por este paladín del liberalismo centroamericano, Darío incluyó el siguiente pasaje que claramente revela las simpatías político-sociales del propio poeta: "Se ha establecido la libertad religiosa; el laicismo en la educación; la justa representación de las minorías ... aumento de escuelas; ley de trabajo en protección de los trabajadores..." "

Como se ve, la lealtad de Darío al programa del Partido Libetal no se redujo a un entusiasmo juvenil. Asimismo es verdad que su interés por los destinos de su pueblo, lejos de extinguirse con el tiempo, creció más y más hasta abarcar su verdadera Patria Grande, que fué todo el mundo hispánico, lo cual consta en tales obras y composiciones individuales como España contemporánea, La carazana pasa, El canto a la Argentina, la "Oda a Colón", la “Oda a Roosevelt", la "Salutación del optimista", la "Ietanía a nuestro ser̃or Don Quijote", y muchas otras en que inequívocamente vibra el inmenso amor de Darío por esa su Patria Grande. Su espíritu cosmopolita y su entusiasmo por la cultura francesa, en particular, han dado raiz a que con frecuencia se le tache de ser un desarraigado de las tradiciones de su propia raza. Es verdad que hubo un tiempo en que el poeta mismo llegó a considerarse más francés que español en lo que se refiere a sensibilidad artística, y así es que en el prefacio de sus Prosas profanas se encuentran esas palabras, hoy famosas: "Abuelo, preciso es decíroslo: mi esposa es de mi tierra; mi querida, de París." Estas, sin embargo, son palabras de la mocedad, y hay que ver que conforme pasa el tiempo se invierte más y más el valor simbólico del orden en que aparecen. Si el poeta las hubiera escrito sólo unos dos o tres años más tarde, ya no habría dicho "mi esposa es de mi tierra; mi querida, de París"; sino "Mi 
querida es de París; pero mi esposa es de mi tierra". Cuando Dario comienza a producir los frutos de la madurez, que son los que indudablemente brotan de lo más hondo de su corazón, se hace más y más evidente que su primera lealtad, su más profundo afecto, $\mathrm{y}$.. en verdad la savia misma de su cultura y sus tradiciones, están inextirpablemente arraigados a la Madre Patria, que él con tanto cariño llama."la España eterna".

Curando La Nación de Buenos Aires envió a Darió a España para que informara acerca del estado en que dicho pais quedaba como consecuencia de la guerra con los Estados Unidos, el poeta escribió en alta mar: "De nuevo en marcha, y hacia el país maternal que el alma americana, americano-española, ha de saludar siempre con respeto, ha de quererla con cariño hondo. Porque si ya no es la antigua poderosa, la dominadora imperial, amarla el doble; y si está herida, tender a ella mucho más". ${ }^{7}$ En España Darío se dedicó a un estudio intenso de la evolución política, económica y social de ese país; de sus características psicológicas; de su vida artística y literaria; y, en fin, de todo aquello que pudiera ayudarle a interpretar los factores que durante siglos habían encauzado los destinos de España trayendo por resultado las tristes condiciones en que el poeta hallaba a la Madre Patria en 1898. Al analizar la catástrofe española, Darío puso la responsabilidad plenamente sobre los dirigentes del país e indicó enfáticamente que las bajísimas normas económico-sociales de las masas no eran un resultado sino más bien una de las principales causas de la decadencia de España. "E1 mal vino de arriba -escribió en uno de sus primeros reportajes-... Entre las cabezas dirigentes hay quienes reconocen y proclaman en alta voz que la causa principal de tanta decadencia y de tanta ruina estriba en el atraso general del pueblo español." ${ }^{3}$ Más tarde, entrando en detalle, exploró todas las esferas sociales poniendo el dedo directamente sobre las llagas del país. Los centenares de páginas que sobre este tema escribió Darío son de especial interés para nosotros por cuanto que ellas revelan claramente la actitud político-social del poeta. Desgraciadamente, el límite de espacio nos permite sólo unas cuantas citas directas. Los siguientes pasajes hablan por sí mismos: "La ignorancia española es inmensa. El número de analfabetos es colosal comparado con cualquier estadística ... EI $11 / 2 \%$ del total del Estado consagra éste en España a la pública 
instrucción, mientras Francia el $61 / 2 \%$, Italia el $21 / 2$, y hasta Portugal el $21 / 4$. No hablemos de Inglaterra, donde el espíritu anglosajón y la riqueza del país, por el mismo espíritu creada, permiten dedicar a la enseñanza el $81 / 2 \%$ del presupuesto total". ${ }^{9}$ En un reportaje consagrado a la posición de la mujer en España, escribió : "Puede asegurarse que en raros países del mundo se presenta el espantoso dato estadístico siguiente: En España 6.700,000 mujeres carecen de toda ocupación, y 51,000 se dedican a la mendicidad. Fueta de las fábricas de tabacos, costuras y modas, y el servicio doméstico, en que tan míseros sueldos se ganan, la mujer española no halla otro refugio... La ociosidad y la miseria, en la clase media y en la baja, son un admirable combustible para la prostitución". ${ }^{10}$ Terminaremos esta sección de nuestro estudio con un pasaje de la magistralmente irónica descripción que hace Darío de la ceremonia del lavapiés ejecutada con gran fausto por la reina de España en el magnífico salón de las columnas. "Por corona —dice Darío-lleva María Cristina una constelación de brillantes, y sutil como una blonda de espuma, la mantilla blanca le cubre el casco de la cabellera... En las tribunas, con los ministros, entre el cuerpo diplomático y los grandes de España, están la infanta Isabel y la Duquesa de Calabria y la Princesa de Austria. En los lados del salón, sentados en bancos negros, hay doce mujeres pobres y trece hombres pobres. No sé que vaga luz brota de esas humildes almas en las miradas ... La reina viene a paso augusto, entre el obispo y el nuncio... De pronto Maria Cristina está ya ciñéndose una toalla, mientras las duquesas, llenas de diamantes, las condesas fastuosas, descalzan a los convidados miserables. La reina con una esponja y con la toalla enjuga los lamentables pies de esas gentes. El representante del Papa vierte el agua de un ánfora. Os digo que por todo pecho presente pasa una conmoción. $\mathrm{Y}$ en ese mismo instante dos voces hablan al oido del observador meditabundo... [Una] hablaba a la oreja izquierda y decía: 'Es hermoso, es un simbolismo grandioso y conmovedor ese acto de humildad... pero, ¿y la miseria? ¿Y los innumerables mendigos que andan por la Corte y por toda Espaua crujiendo de hambre? ... ¿Y la prostitución infantil instalada a los ojos de la capital de S. M. Católica ?"."11

Ante tales manifestaciones de los sentimientos de Darío como las que acabamos de ver, no cabe menos de poner en duda la veraci- 
dad de ciertos escritores que se han empeñado en apocar la figura del poeta con juicios como los de Rufino Blanco-Fombona, cuyas palabras son las siguientes: "Una de las características de la psicología de Rubén - la más lamentable tal vez, ... consiste en que, sin ser hombre de maldad activa, consciente, deliberada... jamás tuvo conmiseración de los débiles ni lástima de la desvalidez."12 En cuanto a las tendencias políticas de Dario, añade Blanco-Fombona: "En política no sólo fué conservador ... sino servil ... Jamás amó la libertad, ni en el fondo, a nuestra América. 'Lo bello en la política es la monarquia', escribió, incapaz de comprender la belleza de la justicia y de la libertad..." 13 A lo cual añade: "Lo que no fuese oro, mármol, fortuna, fausto, le era antipático". ${ }^{14}$ Una opinión mucho más moderada, y por cierto libre del espíritu hiriente que vibra en las palabras de Blanco-Fombona, es la que expresa Leopoldo Lugones, quien, desde su punto de vista de extrema izquierda, caracteriza a Darío en los siguientes términos: "Fué siempre católico, y con ello, monárquico de convicción; pues como no había menester de utilitarias conciliaciones, declaraba sin esfuerzo la evidente incompatibilidad del catolicismo con la república". ${ }^{15}$ Indudablemente, es preciso reconocer que aseveraciones tales como las de BlancoFombona y Leopoldo Lugones, en lo que toca a las alegadas tendencias monárquicas de Dario, no son totalmente fruto de una mente apasionada sino que están basadas, aunque oblícuamente, en ciertos aspectos de la psicología del poeta que dan a estos juicios el valor de una verdad a medias. Darío mismo, en sus hoy célebres "Palabras liminares" de Prosas profanas, dijo: "He aquí que veréis en mis versos princesas, reyes, cosas imperiales, visiones de países lejanos o imposibles: ¡qué queréis!, yo detesto la vida y el tiempo en que me tocó nacer; y a un presidente de República no podría saludarie en el idioma en que te cantaría a ti, ; oh Halagabal! de cuya corte -oro, seda, mármol- me acuerdo en mis sueños." 16 Pues bien, ahora cabe preguntar respecto a estas palabras que a tantos comentarios han dado lugar: ¿Es aquí el observador político quien habla, afirmando la superioridad de la forma monárquica de gobierno sobre la republicana? ¿O es simplemente el poeta y el soñador que, sumido en el mundo de la fantasía, evoca, como él mismo dice, "vi- 
siones de países lejanos o imposibles"? Creemos que las propias palabras del poeta son suficiente respuesta. Además, nos queda aún hastante evidencia que ventilar a este respecto.

Tres años más tarde, Darío escribió una serie de artículos en que, a pesar de su natural amor por la magnificencia y el esplendor, el poeta abordó el tema de la monarquía y la nobleza de casta con un sentido estrictamente realista y crítico, mostrando claramente que lo que para él guardaba un encanto en el mundo de los sueños no debe confundirse con sus convicciones político-sociales. Hablando de la pompa de los monarcas españoles, dijo así: "Los antiguos esplendores, la misma parte estética de la representación real, adquieren hoy un vago prestigio de ópera cómica..." 17 En cuanto a Alfonso XIII en particular, he aquí los juicios del poeta: "La imaginación del príncipe niño se impresiona desde el comienzo de su despertamiento a la existencia que le rodea, con las manifestaciones de una vida falsa o equívoca. No será sino con harta dificultad que la noción. de soberanía que ha penetrado en su cerebro, pase a la noción de una existencia democrática." 18 En otro artículo, no vaciló en denunciar a la aristocracia tradicional. "En nuestras sociedades modernas - dijo Darío- lo que caracteriza a la nobleza es su ociosidad, su ineptitud para el trabajo... Nada señala que la patria española pueda esperar algo de su aristocracia". 19

En varias ocasiones Darío usó el término democracia en forma despectiva con referencia ya a lo que él interpretaba como utilitarismo yanqui, ya a la mediocridad del intelecto y al achatamiento espiritual. El hecho de que determinadas manifestaciones de la democracia hirieran la susceptibilidad artística del poeta, o le fueran odiosas por razón de la aristocracia de espiritu que lo caracterizaba, no quiere decir, sin embargo, que Darío rechazara la forma democrática de gobierno ni que prefiriera la monarquía a la república. Su cuento "Las razones de Ashavero", 1893, viene muy al caso para estudiar las paradójicas reacciones que experimentaba Dario como poeta y artista, por una parte, y, por la otra, como pensador político. "En un país ... que probablemente no aparece en ninguna de las cartas geográficas conocidas - nos dice el poeta- quisieron los habitantes darse la mejor forma de gobierno. Fueron tan cuerdos que, para mejor obrar, ... se dirigieron para consultar con un poeta, el cual les contestó: 'Pensaré y os aconsejaré lo que debéis de hacer...' Y 
como era ese poeta más poeta que el rey Salomón, hablaba y comprendía la lengua de los astros, de las plantas, de los animales... Fuése pues el primer día al campo, meditando en cuál sería la mejor forma de gobierno. Bajo un frondoso roble halló echado a un león. ... 'Señor rey -le dijo-... ¿querría decirme cuál es para un pueblo la mejor forma de gobierno?' [A los cual contestó el león:] 'Ingrato... i Nunca pensé que desde que Platón os arrojó cruelmente de su república pudiéseis poner en duda las ventajas de la monarquía, vosotros, los poetas! Sin la pompa de las grandezas reales no tendríais para realzar vuestros versos ni púrpura, ni oro, ni armiño ... El crinado numen ha prohibido que se pronuncie la palabra democracia en su imperio. La república es burguesa; y alguien ha hecho observar que la democracia huele mal... Por lo que a mi toca os diré que los pueblos más felices son aquéllos que son respetuosos con la tradición; y que desde que existe el mundo, no hay nada que dé mayor majestad a la floresta que el rugido de los leones. Así, pues, ya conocéis mi opinión: monarquía absoluta'." $\mathrm{El}$ águila, como el león, favoreció la monarquía; el tigre se puso de parte de la dictadura militar; el gorrión cantó las ventajas de la república; la rosa respondió: "Nosotras no sabemos de política más que lo que murmura don Diego de noche y el girasol de día ... no tengo más opinión que esta: I a belleza sobre todo." Venus dió respuesta semejante. Al tercer día encaminóse el poeta a la ciudad a dar respuesta a los habitantes, abrumado por tan diversas opiniones. "De repente vió venir un viejo encorvado como un arco, que tenía barbas largas... y sobre los blancos bigotes una curva nariz semítica..." Explicóle el poeta el caso en que se encontraba, y he aquí la respuesta del Judío Errante, que no era otro el viejo en re- . terencia: "Sabes que es verdad conocida que el diablo no sabe tanto por diablo cuanto por viejo... He vivido tanto que mi experiencia es mayor que el caudal de agua del océano. ¡Así también es de amarga! Mas he de decirte que en lo que respecta al modo mejor de regir las naciones, no sabría con toda exactitud señalarte éste o el otro. Porque desde que recorro la tierra he visto los mismos nales en repúblicas, imperios y reinados ... Por eso debo decirte que no está en la forma de gobierno la felicidad de un país, antes bien en la elección de aquéllos que dirijan sus destinos, sean jefes republicanos o majestades de derecho divino." 20 
El momento histórico en que Dario se enfrentó con la escena política española, que estaba amargamente dividida entre monárqui$\cos$ y republicanos, nos of rece abundante oportunidad para estudiar las simpatías e inclinaciones del poeta. No hallamos indicación de que Daría, ante el entonces relativamente reciente fracaso de la primera república, favoreciera el establecimiento inmediato de una segunda república. Pero sí hallamos amplia evidencia de que las personalidades del día que él más altamente admiraba y ensalzaba con su pluma eran precisamente los paladines de la democracia española, los pensadores y hombres de acción que durante las últimas décadas habían sido el sostén y alma del movimiento republicano. El célebre dirigente de este movimiento, y presidente de la primera república, don Emilio Castelar, fué nada menos que uno de los ídolos de Darío y el objeto de cuatro de sus más vigorosas composiciones en prosa, escritas en diferentes épocas de la vida del poeta. ${ }^{21} \mathrm{~A}$ la muerte de Castelar, Darío le consagró un largo y sentido ensayo estudiando al hombre, al orador y al pensador y dirigente político. Después de ensalzar al pueblo español por el alto tributo que supo rendir a su jefe en las ceremonias funerales, Darío enérgicamente levantó su voz en protesta contra el gobierno de S. M. María Cristina por la mezquindad de los honores oficiales que tuvo a bien rendir al ilustre jefe republicano en la ocasión de su muerte. Refiriéndose a la ceremonia fúnebre, escribió el poeta: "En aquellos momentos las cámaras italiana y portuguesa enviaban su pésame a ese mismo gobierno mezquino; el senado de la república argentina se ponía de pie; el autocrático gobierno ruso manifestaba su pesar... La prensa de la tierra se enlutaba, el pensamiento universal estaba de duelo... España queda hoy sin su representante emersoniano, sin el hombre noble que fué en su siglo lengua y gesto de su raza ... En el tiempo de su aparición, el espíritu democrático era lo más avanzado, lo más atrayente para los espíritus libres; la forma del progreso." 22

Terminaremos el presente estudio con la opinión de Dario sobre dos figuras más de entre las personalidades máximas del movimiento republicano español a fines de siglo. Después de lamentarse de la demasiada fecundidad literaria de Galdós, a expensas de sus capacidades artísticas, Darío comenta: "Bien podría el señor Galdós dar a España un libro cada año, en el cual libro pusiese la esencia saludable de su pensamiento y ayudase a la obra social y al resur- 
gimiento de la nación española." 23 En otro artículo, después de calificar al conservador Pereda de "espíritu fósil", Dario pasa a decirnos: "El valenciano Blasco lbáñez es fuerte, enérgico, sencillo como un árbol... Como a todos los pensadores contemporáneos, . preocúpale el áspero problema del hombre y de la tierra, y está naturalmente con los de abajo, con los oprimidos... En La barraca se exterioriza en las musculaturas del estilo de uno de esos espíritus de gladiador, o de robusto constructor, a la Zola ... Libros como ése no se hacen por puro culto al arte, sino que llevan consigo hondos anhelos humanos; son páginas bellas, pero son también generosas acciones y empresas apostólicas." 24

Amigos intimos de Darío repetidamente to han calificado de "gran sencillo y gran complicado." 25 Es preciso tener en cuenta esta paradójica característica al estudiar cualquier manifestación del espíritu del poeta. En lo que respecta a sus tendencias político-sociales, la inevitable paradoja se manifiesta en términos del conflicto entre el poeta y soñador, y el pensador político. Después de examinar su vasta obra bajo esta luz, llegamos a la conclusión de que, en total de cuentas, el monto de los escritos de Darío a través de su rida está muy lejos de confirmar la tesis de que el poeta se mantuvo impasible ante el problema social y que sus convicciones politicas fueron conservadoras, monárquicas y anti-republicanas. La evidencia total que resalta de su obra revela precisamente todo lo contrario.

ANTONIo M. DE LA TORRE,
University of Oklahoma.

NOTA S

1 Véanse notas 12-15.

2 Bancroft, Hugo, West American History, San Francisco, California, The History Company Publishers, vol. virr, 1887, pp. 472-485, y Darío, Rubén, El viaje a Nicaragua, Madrid, Editorial Mundo Latino, 1919, pp. 111-121.

3.5 Dario, Rubén, El viaje a Nicaragua. Madrid, Editorial Mundo Latino, p. 204 . 43-68.

4 Darío, Rubén, Crónica política. Madrid, Fernández Fè, 1924 (?), pp. 
5 Darío, Rubén, El viaje a Nicaragua. Madrid, Ediorial Mundo Latino, 1919, pp. 155-162.

6 Ibid, pp. 117-118.

7 Darío, Rubén, España contemporánea. Madrid, Editorial Latino, 1919, p. 1.

8 Ibid., p. 22.

9 Ibid., pp. 241-247.

10 Ibid., p. 327.

11 Ibid, pp. 96-97.

12 Blanco-Fombona, Rufino, El modernismo y los poetas modernistas. Madrid, Editorial Mundo Latino, 1929, pp. 165-166.

13 Ibid., p. 152. Blanco-Fombona no indica de dónde sacó la cita que le atribuye a Darío. Nosotros no hemos podido hallar tales palabras en la obra del poeta. No sería esta la primera vez que Blanco-Fombona faltara a la verdad para tratar de rebajar a Darío; véase la serie de contradicciones en que incurre en su crítica de Darío, op. cit., pp. 147-188. El y Gómez Carrillo evidentemente se propusieron desprestigiar al poeta sin respeto alguno a la verdad. Véase Gómez Carrillo, Enrique, Obras completas. Madrid, Editorial Mundo Latino, 1918, vol. X, pp. 219-220.

14 Ibid., p. 166.

15 Dario, Rubén, Poemas escogidos. Prólogo de Leopoldo Lugones. México, Lectura Selecta, 1919, pp. 16-17.

16 Darío, Rubén, Prosas profanas. París, Librería de la Vda. de Bouret, 1901, pp. $48-49$.

17 Darío, Rubén, España contemporánea, p. 121.

18 Ibid., p. 121.

19. Ibid, pp. 302-304.

20 Darío, Rubén, Escritos inéditos. New York, Instituto de las Españas, 1938, pp. 21-24.

21 Dario, Rubén, "Un Sermón (en la Basílica de San Pedro)", en Obras completas. Madrid, Renacimiento, 1923 (?), vol. rv; y "Un recuerdo de Castelar", "En casa de Castelar" y "Pensadores y Artistas", respectivamente, en los volúmenes virr, XIX y XxII de las Obras completas, de la serie Editorial Mundo Latịno, Madrid, 1917-1919.

22 Darío, Rubén, Cabezas. Madrid, Editorial Mundo Latino, 1919, pp. 139167. 
23 Daría, Rubén, España contemporánea, p. 234.

24 Ibid., pp. 185-186.

25 Soto-Hall, M., Revelaciones intimas de Rubén Dario. Buenos Aires, E1 Ateneo, 1925, p. 216. Soto-Hall es uno de varios biógrafos de Darío que se han referido a esta característica de la psicología del poeta. 